\title{
GIS and Remote Sensing Applications for Resource Mapping
}

\section{Abstract}

Nepal has several natural resources like forest, soil, water and minerals which could contribute to the national economy as well as to the livelihood of people. Forest is major resource to contribute as mentioned. Forest has two way of contribution i.e. ecological and economic. The horizontal extent of the forested land is diversely differing from place to place. In this context the resource mapping is essential to have an idea of resource type, its distribution in geographic domain and land coverage of resources. There are several techniques of resource mapping, from sketch mapping to the GIS and Remote sensing based resource mapping. The bases of selecting alternatives are precision of map, interoperability of the product, and investment of time, money and labour and comparatively GIS based resources maps seems more convenient.

Keywords: Remote Sensing, GIS, GPS, Resource Mapping, Forest Introduction

Nepal is a mountainous country and has huge source of natural resources i.e. forest, soil, water and minerals. Forest is such renewable natural resource which is the basis for the human civilization. The spatial extent of the forest in the world is widespread and the spatial distribution of forest plays vital role in natural and human interfered activities in the world. The natural phenomenon on the earth is interrelated to land, water and ultimately with atmosphere. Human civilization and the animal existence is rooted on forestation in the world. Before the civilization, earth passed through the era of forestation and wild nature. As we hugely pronounced that forest is such natural resource which play vital role in human civilization to livelihood of the people. As it contributes majorly in national economy and in the ecology of the landscape, forest is that resource which is important for ecology, people and their livelihood. On the same way, the spatial distribution and extent of resource and its type are important in resource planning and management (Roy and Joshi, 2002). The geographic extent and distribution of resources will act majorly in resource management and utilize those resources. The quality of forest and type of forest and the distance from the villagers to the forest resources is crucial while we talk about the local peoples' livelihood and dependency in forest products (Shrestha, 2005).

This article is not prepared from exact work in the field. This article comprises some examples from own works and some from literature reviews and textbooks. The main aim of this article is to overview the techniques of resource mapping using geospatial technologies.

\section{What GIS is?}

Geographic Information System which is acronymed by GIS is a computer based system of data acquiring, data storage, data management, analysis and display of geographic data in relation to real world (Burrough and McDowell, 1998). There is a long history of the development of GIS. Before the development of GIS, there was a practice of mapping and cartographic activities with hand practices and other mechanical tools. After the invention of digital media like third generation computers, advance plotters and web applications, the recent development of geospatial technologies were developed. There are numerous products of geospatial analysis systems like ArcView, ArcGIS, ILWIS, Arclnfo etc. What RS is?

Remote sensing is a technology of assessing the object without physical contact. Based on the platform and sensors used, remote sensing can be classified as Aerial and satellite data and based on the sensors and EMR used, it could be classified as active and

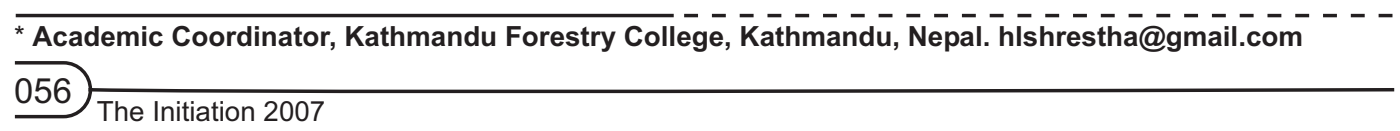


passive. Active remote sensing will use own source of energy and passive remote sensing will use the energy from sun. These days, increasing resolution capability is the point of attraction in remote sensing data. Resolution may be in four aspects i.e. spatial, spectral, radiometric and temporal (Lillesand and Keifer, 1994). High resolution data are being produced and available from few companies i.e. $1 \mathrm{~m}$ resolution data with $11 \mathrm{bit}$ and 4 band data by IKONOS and $0.6 \mathrm{~m}$ resolution data with 8 bit and 4 band data by QuickBird. Indian remote sensing is also producing high resolution data at $5.6 \mathrm{~m}$ spatial resolution and they are planning to produce $1 \mathrm{~m}$ resolution from ResourceSat.

\section{What resource mapping is?}

While we are appreciating the contribution of natural resource in human civilization, industrial development, urbanization, and livelihood of the people, it is very important to assess the resource types, its availability and its spatial distribution on the land. The resource types and its availability can be assessed by different resource assessment techniques and the spatial extent of resources can be assessed using remote sensing, GIS and GPS technologies. When we talk about the spatial and geographic extent of the resources, a term resource map is coined. Resource map will give us information on resources, its geographic extent, georeferenced information in relation to real world coordinates. Thus resource mapping is the technique to visualize the level of resources, varieties of resources, spatial extents of the resources in geographic domain in the form of graphical representation of the data i.e. map. This technique will support to the resource manager to develop better plan, implement the plan for better management and do modeling for the future resource availability and management actions.

\section{Traditional techniques of resource mapping : Participatory mapping i.e. PRA and RRA}

There are some conventional techniques of resource mapping. Some preliminary technique is prepares the sketch map of the micro level of geographic zone by field observation and from the expert knowledge of the observer. This will include very preliminary snaps of the resources types and its spatial extent.

The other technique of resource mapping uses participatory techniques for mapping using some tools i.e. PRA and RRA tools. By using local materials, people will participate actively and prepare resource map at local micro level. This technique is quite appropriate for gathering one level of information from the locality for the externals which may be later capitalized and applied for planning and management options. In one and other sense, it is tentative information gathering technique.

This technique has two issues missing i.e. precise mapping of the resources and geographic coordinates. Precise mapping is necessary while we are intervening some action in micro level and to relate with world wide interventions we need exact geographic relations.

\section{Importance of resource mapping:}

Resource map itself gives information to local users about the generic snapshot at micro level. This plays important role in utilization and maintains sustainability because local people may have only individual and very minor level of perception on utilization of resources which is mainly needed and demand driven. The resource map can help to have generic level of perception at least in micro level to the local users. The resource maps also give information about the generic level for the micro level resources for externals, resource managers and researchers which could help to get generic information at community level and help to apply system approach to manage and to recommend the utilization approaches. Thus resource map could help during the plan formulation, implementing the plan in action, applying management actions and harvesting and marketing strategies which could lead resource and community towards the sustainability. Here the term sustainability may include both resource and livelihood issues. 


\section{Participatory Versus precise mapping of resources}

As explained earlier, the participatory resource mapping will give the tentative idea of the resources, the recent mapping techniques with the input of GIS, GPS and remote sensing support to prepare precise map which is very essential plan formulation and manage the resources for sustainability. By implying precise maps and getting knowledge on resources availability and distribution, livelihood could be easier mainly in case of forest based resources and products i.e. NTFP available area and their areal extent. This will help to establish any enterprise or individual resource utilization scheme to incorporate the system approach and sustainability.

\section{Precise mapping techniques}

There are several techniques for precise mapping using GIS, GPS and remote sensing technologies. Some of those are explained hereby.

\section{Photomap: Arial photographs}

Even though aerial photo is not having same scale in entire photos because of topographic distortion and having some radial displacement from the center of photo towards the edge of photo, photomap is a product of aerial photogrametry which is equivalent to paper map as it is prepared distortion free and projected in reference to geographic referencing system. Photomaps are prepared using series of aerial photos with $60 \%$ overlap and $30 \%$ side lap of the same resource areas by means of digital photogrametry techniques in Leica Photogrametry Suite (LPS) or ERDAS Imagine Ortho Engine or other programmes. Photomap is in real sense ortho photo which means photos equivalent to orthographic projection (See ERDAS Imagine Field Guide).

In this technique, firstly acquired aerial photos in dia-positive will be scanned in image format. Those will be entered in ortho engine of any programme i.e. LPS or ERDAS Imagine. Tie points and control points will be collected from the field by using precise reading of GPS technology at least two for single set of overlapped photos which are called GCPs. Orthophoto of all sets of overlap will be prepared and those will be mosaicked and prepared single product as photomap.

Resource managers or local users can prepare resource map by using photomap which is the product orthophoto techniques as it is similar to the projected map. It will give exact location of resources and area coverage of the resources or resource types by visual interpretation and digitizing with manual effort in GIS environment.

\section{Integration with GPS surveying}

The basic objective of resource mapping is to locate the resource available zones and find the area of land cover by the resources. Conventionally, we are used to do so by using chain surveying and compass surveying techniques. It is felt that those are more inconvenient techniques because those are more labour demanding, time consuming, expensive and approximate. Thus, rather than stretching chain and tapes and using ranging techniques, nowadays convenient techniques are being adopted for resource mapping (Shrestha, 2006) i.e. GPS surveying and using Total Station. The main aim of using these machines is finding the latitude, longitude and altitude of each and every point. If those points were a set of close traverse, those could form a polygon in GIS environment and give information of land cover area by the resources. If those are only point or a set of lineage, those will give spatial distribution pattern of the resources

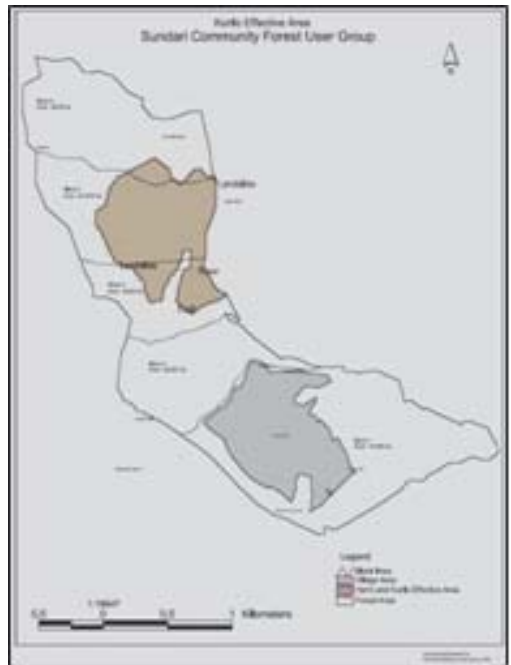

Figure1 Boundary Survey of Sundari CF using GPS 
and the linear extent of the resource correspondingly. Only the matter is, this technique is also not that much magica technique as provoked, we should also go around the resource zone and track GPS reading or take reading from the Total Station for each and every points which ultimately contribute to prepare resource map at micro level. This technique is more convenient in micro level because it is difficult to travel around the resource zone at huge level i.e. meso level, national or regional level.

\section{Geostatistical technique: Point Maps (distribution maps)}

The resource map in another way can be prepared by using geostatistical techniques. In this method GIS based resource map can be prepared by using field measured point data. By using statistical means field point data of resources will be collected and based on those point data continuous resource map will be prepared using some interpolation techniques i.e. kriging, co-kriging etc (See ILWIS user's manual). This tool can be found in most of software i.e. ILWIS, IDRISI, ArcGIS etc.

This resource map will be precise and accurate if it is prepared with the precise field measurement of the resources and the geographic location. This technique will be helpful while we are going to interpolate and prepare resource map of large area.

\section{Forest classification maps}

Resource map of forested area can also be prepared by using remote sensing data. Remote sensing data are widely varied in various aspects i.e. sensors, spatial resolution, radiometric resolution, company and platform. There are active and passive sensor data, course to high resolution data i.e. $30 \mathrm{~m}$ to $0.6 \mathrm{~m}$ data, 8 bit to 11 bit radiometric data, PAN, Multispectral to Hyperspectral data. Those data have own capacity to interpret the specific earth features i.e. hyperspectral data are more useful to prepare resource map of below ground resources. The choice of the satellite image depends upon the type resources for which we are going to prepare a resource map. Thus in the use of satellite image data too, there are several techniques and methods of preparing resource maps like hard classification or pixel based classification, object oriented classification (Pekkarinen, 2002) and fuzzy classification. In case of hyperspectral data,

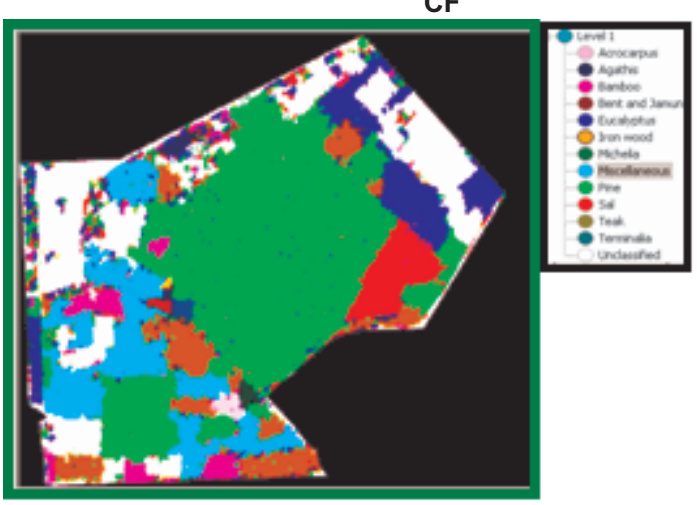

Figure 4 Forest classification Map of FRI Dehradun

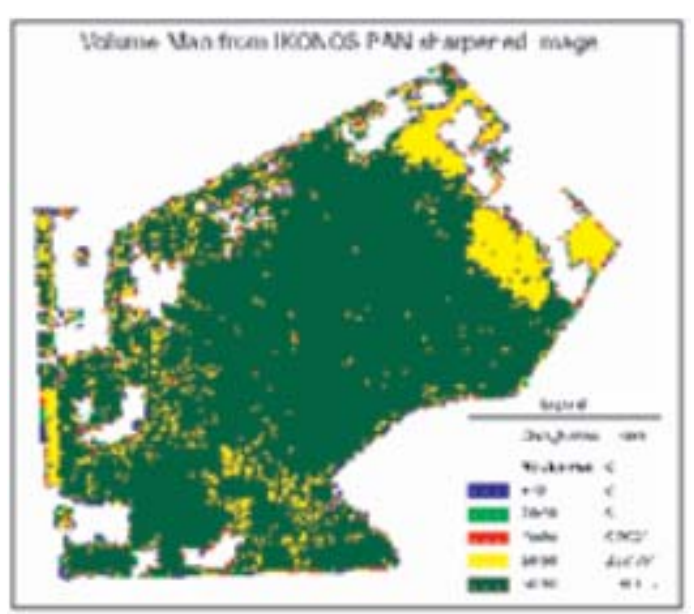

Figure 4 Forest classification Map of FRI Dehradun subpixel classification technique also can be adopted and in case of RADAR and SAR data, a technique of interferometry should be applied. These techniques support resource managers or analyst to prepare land use land cover map, forest classification map, NTFP availability map, forest type based on species, stock level or density etc. (Shrestha, 2004). 
In these techniques, field measurement data and ground truth data are essential during the process of classification of satellite images. The ground truthing may be GPS reading, aerial photographs of the same dates or other existing maps i.e. topographic maps, land use land capability maps. This information is essential to train the computer to classify images for better representation of real resource stock and its spatial extents.

\section{Timber Volume maps}

Multi-source forest inventory techniques can prepare directly volume maps (or stock maps) of the forest resources with the inputs from remote sensing, GIS, GPS technologies. This technique is being applied as a good alternative for conventional forest inventory. Conventional forest inventory only rely on the field measurement of the individual trees. In this technique, location of sample plots measured in the field will be overlayed over the satellite images. Plotwise stock level will be calculated from field measured data. The average pixel data of the overlayed sample plots for all samples will be calculated from satellite image. The regression relation will be assessed between field measured stock level and the average pixel value of sample plots. Regression equation will be established for each species against the different band of satellite image. Based on the established regression equation, continuous timber volume map could be prepared. This kind of resource map will give information about the species type and their stock level of the entire forest stand (Shrestha, 2004).

The same kind of resource map can be prepared by using some mathematical algorithms which could be established among stock level, forest type, field measurement (sample plots) and preparing a prototype of computer application which broaden the application of advance technologies i.e. computer programming, GIS, Remote sensing etc for example k-means, c-means etc.

\section{Conclusion}

Thus it can be concluded that there are several techniques to prepare resource map. The selection of alternatives depends on requirement of the analyst, type of required output, possible inputs etc. There is a long journey of resource mapping from sketch map to the advance GIS map. Anyone can prepare resource map at their own convenience considering the requirement, investment of money, time and form of the output. Still it can be concluded that GIS and RS based resource mapping techniques are more convenient, less time consuming, interoperable to the advance technologies and precise.

\section{References}

Burrough, P. A. and McDonnell, R. (1998), Principles of Geographic Information Systems, Oxford University Press, U.K.

Christ, H. (1999), Participatory Land Use Planning in Cambodia, Main Report, Proceedings of the Introductory Workshop, 14 - 15 September 1999.

Cohen, W. B., Mairsperger, T. K., Spies, T. A., and Oetter, D. R. (2001), Modelling forest cover attributes as continous variables in a regional context with Thematic Mapper data, International Journal of Remote Sensing, Vol(22), No. 12, p2279-2310

Giakoumakis, M.N., Gitas, I.Z. and San-Mibuel, J. (2002). Object-oriented classification modelling for fuel type mapping in the Mediterranean, using LANDSAT TM and IKONOS imagery-preliminary results, Forest Fire Research and Wildland Fire Safety, Viegas, ISBN 90-77017-72-0.

Jordan, G. and Shrestha, B. (2000), A Participatory GIS for Community Forestry User Groups in Nepal: Putting People Before the Technology, PLA Notes 39

Lillesand, T. M. and Keifer, R. W. (1994), Remote Sensing and Image Interpretation, John Wiley \& Sons, NY, Third Edition.

Mahato, B. (2001). Quantification of forest growing stock using remote sensing data for planning and management: A case study of Tikauli forest in Chitwan District, Nepal. Paper presented at the 22nd Asian Conference on Remote Sensing, 5-9 November 2001, Singapore. 
Pekkarinen, A. (2002), Image segment-based spectral features in the estimation of timber volume, Remote Sensing of Environment, 82, 349-359.

Roy, P. S, and Joshi, P. K., 2002, Forest cover assessment in north-east India-the potential of temporal wide swath satellite sensor data, International Journal of Remote Sensing, Vol 23 No. 22, p 4881-4896

Shrestha, B. and Tuladhar, B. R. (....), Geomatics in Participatory Community-based Forest Resources inventory in the middle mountains of Nepal,

Shrestha, H. L. (2004), Comparative Evaluation of Different Spatial Resolution Satellite Data for Timber Volume Estimation, paper submitted and accepted for the seminar "High Resolution Mapping" held in Hannover, Germany.

Shrestha, H. L. (2005), GIS application in NTFP management, Hamro Ban Sampada (in Nepali) Vol. 3 (1), ForestAction, Nepal. Website: www.forestaction.org

Shrestha, H. L. (2005), GPS mapping of community forest for NTFP management, presented in a seminar organized by Nepal GIS Society entitled "Mapping the world, Today ,Tomorrow and in the Future for planning as well as Decision Making Process", in July 22, 2005, on the way to publish.

Shrestha, H. L. (2006), Using Global Positioning Systems (GPS) and Geographic Information System (GIS) in Participatory Mapping of Community Forest In Nepal, EJISDC (2006)25,5, p1-11 http://www.ejisdc.org

Singh, I.J., Das, K. K., and Kushwaha, S. P. S., (2003). Forest Stock Assessment using IRS LISS III and PAN merged data in Timli Forest Range, Dehradun. Journal of the Indian Society of Remote Sensing. Vol. 31, No. 1, 49-56

T. Tokola and Shrestha, S. M., (1999) "Comparision of cluster-sampling techniques for forest inventory in southern Nepal", Forest Ecology and Management, 116, p219231

Wallerman, J. (2003). Remote Sensing Aided Spatial Prediction of Forest Stem Volume, Doctoral Thesis, Swedish University of Agricultural Sciences, Umea.
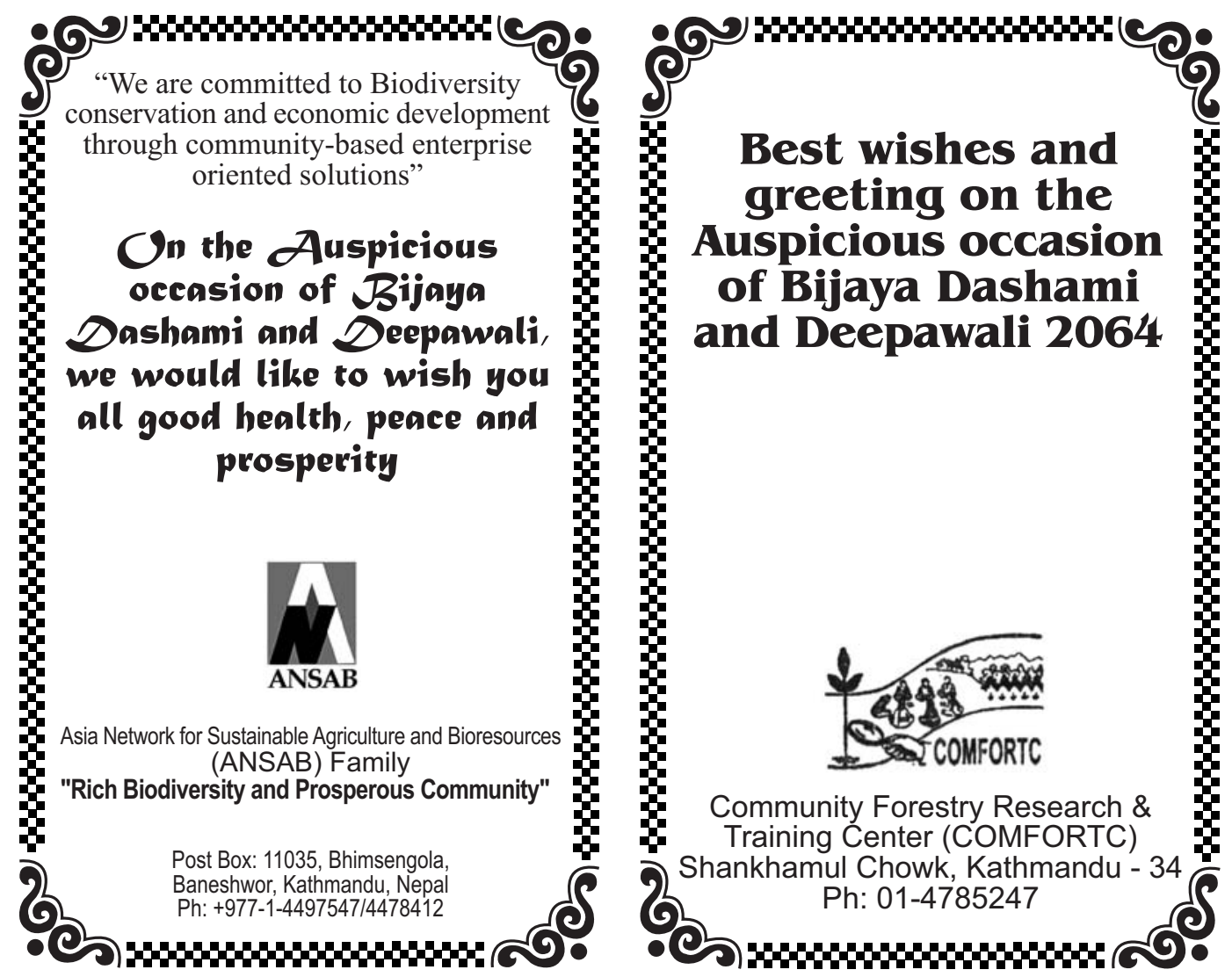